\title{
PENGEMBANGAN SISTEM PRESENSI DAN KEDISIPLINAN DOSEN TERHADAP BIAYA OPERASIONAL PERGURUAN TINGGI
}

\author{
Agus Wantoro \\ Sistem Informasi, STMIK Teknokrat \\ Jl.ZA Pagar Alam No.9-11 Kedaton, Bandar Lampung, Indonesia \\ Email : aguswantoro87@gmail.com
}

\begin{abstract}
ABSTRAK
Salah satu tugas dosen adalah melaksanakan tri darma perguruan tinggi yaitu melakukan pengajaran. Beberapa perguruan tinggi, presensi dosen mengajar masih dilakukan tulis tangan yang dilakukan oleh dosen yang bersangkutan dengan mengisi form presensi dosen. Bagi dosen yang tidak dapat mengajar sesuai jadwalnya, maka akan ditulis sebagai ketidakdisiplinan dosen yang dicatat manual kedalam form kesiplinan dosen oleh staf tata usaha setiap minggu. Sistem ini masih digunakan dibeberapa perguruan tinggi di Indonesia
\end{abstract}

Berdasarkan sistem yang saat ini berjalan, terdapat beberapa kelemahan seperti manipulasi presensi dosen yang tidak mengajar tetapi menulis pada daftar kehadiran atau presensi dosen. Dosen mengisi presensi terkadang tidak rutin sesuai jam mengajar yang mengkibatkan dosen tidak sesuai dengan jam mengajar yang dapat merugikan instansi. Penggunaan kertas yang digunakan mengisi presensi menggunakan biaya yang tidak sedikit, dengan jumlah dosen 120 yang menggunakan form presensi 2 lembar, maka membutuhkan 240 lembar per bulan dengan biaya Rp.48.000. Jika dalam 1 tahun, maka biaya yang dibutuhkan sekitar Rp.576.000. Setiap akhir bulan pembuatan rekap presensi dosen membutuhkan waktu yang sangat lama sekitar 8 jam. Selain presensi dosen, rekap kedisiplinan membutuhkan waktu 30 menit yang rutin dilakukan setiap minggu. Selain itu, pemantauan beban jam kerja dosen belum termonitor dengan baik.

Menggunakan sistem presensi dan pengolahan data kedisiplinan dosen secara komputerisasi, untuk melakukan presensi dosen tidak perlu mengisi form kehadiran karna sudah dilakukan oleh staf tata usaha. Kesalahan presensi dosen dapat berkurang. Pembuatan rekap presensi dosen lebih mudah dan cepat hanya membutuhkan waktu 1 menit. Biaya operasioanl berkurang Rp.576.000/bulan karna tidak perlu menggunakan form presensi dosen. Rekap kedisiplinan setiap minggu hanya membutuhkan waktu 30 detik

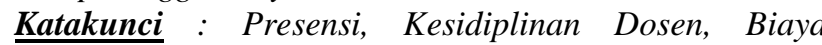
Operasional

\section{PENDAHULUAN}

Dosen dituntut melaksanakan tridarma perguruan tinggi yang meliputi pengajaran dan pembimbingan, penelitian, serta pengabdian kepada masyarakat. Berdasarkan Permendikbud RI No. 84 tahun 2013 tentang Pengangkatan Dosen Tetap non Pegawai Negeri Sipil pada Perguruan tinggi Negeri dan Dosen Tetap pada
Perguruan Tinggi Swasta pasal 9 ayat 2. Beberapa perguruan tinggi, melakukan presensi dosen mengajar masih dilakukan tulis tangan yang dilakukan oleh dosen yang bersangkutan dengan mengisi form presensi dosen. Bagi dosen yang tidak dapat mengajar sesuai jadwalnya, maka akan ditulis sebagai ketidakdisiplinan dosen yang dicatat kedalam form kesiplinan dosen oleh staf tata usaha setiap minggu. Sistem ini masih digunakan dibeberapa perguruan tinggi di Indonesia

Berdasarkan sistem yang saat ini berjalan, maka terdapat beberapa kelemahan seperti manipulasi presensi dosen yang tidak mengajar tetapi menulis pada daftar kehadiran atau presensi dosen. Dosen mengisi presensi terkadang tidak rutin sesuai jam mengajar yang mengkibatkan dosen tidak sesuai dengan jam mengajar yang dapat merugikan instansi. Penggunaan kertas yang digunakan mengisi presensi menggunakan biaya yang tidak sedikit, dengan jumlah dosen 120 yang menggunakan form presensi 2 lembar, maka membutuhkan 240 lembar per bulan dengan biaya Rp.48.000. Jika dalam 1 tahun, maka biaya yang dibutuhkan sekitar Rp.576.000. Setiap akhir bulan pembuatan rekap presensi dosen membutuhkan waktu yang sangat lama sekitar 8 jam. Selain presensi dosen, rekap kedisiplinan membutuhkan waktu 30 menit yang rutin dilakukan setiap minggu.

\section{LANDASAN TEORI}

\section{A. Pengembangan Sistem}

Penyusunan suatu sistem yang baru untuk menggantikan sistem yang lama secara keseluruhan atau memperbaiki sistem yang telah ada [1]. Sistem yang lama perlu diperbaiki atau diganti disebabkan karena beberapa hal, seperti permasalahan-permasalahan (problems) yang timbul di sistem yang lama yang dapat berupa Ketidakberesan dalam sistem yang lama menyebabkan sistem yang lama tidak dapat beroperasi sesuai dengan yang diharapkan

\section{B. Presensi}

Menurut Kamus Besar Bahasa Indonesia, presensi merupakan kehadiran atau daftar hadir bagi seseorang pada suatu organisasi maupun kegiatan [2]
C. Dosen
Dosen adalah pendidik profesional dan ilmuwan dengan tugas utama mentransformasi-kan, mengembangkan, dan menyebarluaskan ilmu 
pengetahuan, teknologi, dan seni melalui pendidikan, penelitian, dan pengabdian kepada masyarakat [8]

\section{Biaya Operasional}

Proses pengelompokan secara sistematis atas keseluruhan elemen yang ada di dalam yang lebih ringkas untuk dapat memberikan informasi. Penggolongan biaya operasional tergantung untuk apa biaya tersebut digolongkan dan untuk apa di perlukan. Tidak ada konsepsi biaya yang dapat memenuhi berbagai macam tujuan, oleh karena itu terdapat bermacam macam penggolongan biaya operasional [6]

\section{E. Unified Modelling Language (UML)}

Bahasa pemodelan standar. Jika menggunakan UML harus dapat membuat model-model yang dapat berhubungan satu dengan yang lainnya dengan mengikuti standar yang ada [5]. UML diaplikasikan untuk maksud tertentu, biasanya digunakan untuk merancang sebuah perangkat lunak, sebagai sarana komunikasi antara perangkat lunak dengan proses bisnis, digunakan pula untuk menjabarkan sistem secara rinci untuk analisa dan mencari apa yang diperlukan suatu sistem, serta sebagai dokumentasi sistem yang ada, proses-proses dan organisasinya. UML menyediakan beberapa jenis diagram yang menggambarkan model-model perangkat lunak yang akan dibuat

\section{F. Tinjauan Study}

Tabel 1. Daftar Literatur

\begin{tabular}{|c|c|c|}
\hline $\begin{array}{l}\text { Judul dan } \\
\text { Pengarang }\end{array}$ & Pembahasan & Hasil \\
\hline $\begin{array}{l}\text { Sistem absensi } \\
\text { asisten dosen } \\
\text { menggunakan } Q R \\
\text { Code } \\
\text { scannerccBerbasis } \\
\text { android } \\
\text { (Mukhamad } \\
\text { Taqwa Nuddin, } \\
\text { Diana Laily Fithri, } \\
\text { 2005)[3] }\end{array}$ & 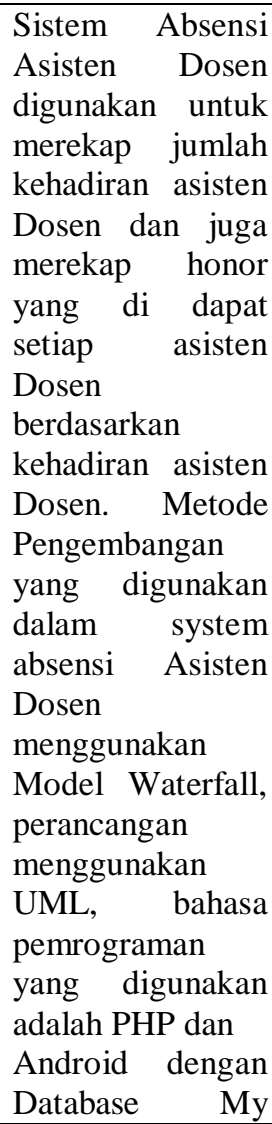 & $\begin{array}{l}\text { Aplikasi } \\
\text { berbasis } \\
\text { Android, } \\
\text { QRCode dan } \\
\text { web untuk } \\
\text { Asisten } \\
\text { Dosen }\end{array}$ \\
\hline
\end{tabular}

\begin{tabular}{|c|c|c|}
\hline & $\begin{array}{l}\text { SQL. Teknologi } \\
\text { menggunakan } \\
\text { QRCode untuk } \\
\text { pengambilan data } \\
\text { absensi }\end{array}$ & \\
\hline $\begin{array}{ll}\text { Perancangan } \\
\text { sistem informasi } \\
\text { absensi dosen dan } \\
\text { mahasiswa } \\
\text { Universitas } \\
\text { Sumatera Utara } \\
\text { (Dedi Eka Putra } \\
\text { Nasution, 2009) } \\
\text { [4] }\end{array}$ & $\begin{array}{l}\text { Permasalahan } \\
\text { yaitu pada absensi } \\
\text { dosen dan } \\
\text { mahasiswa mesih } \\
\text { menggunakan } \\
\text { manual sehingga } \\
\text { terdapat permasalahan } \\
\text { manipulasi data. } \\
\text { Berdasarkan } \\
\text { permasalahan } \\
\text { dikembangkan } \\
\text { menggunakan } \\
\text { sistem informasi } \\
\text { berbasis web } \\
\text { yang dapat } \\
\text { mempermudah } \\
\text { dalam mengolah } \\
\text { data absensi } \\
\text { dosen dan } \\
\text { mahasiwa. } \\
\text { Adanya sistem } \\
\text { informasi mdapat } \\
\text { membantu mempermudah } \\
\text { pengolahan data } \\
\text { absensi }\end{array}$ & $\begin{array}{l}\text { Aplikasi } \\
\text { berbasis web } \\
\text { yang mampu } \\
\text { mempermud } \\
\text { ah } \\
\text { pengolahan } \\
\text { data absensi } \\
\text { dosen dan } \\
\text { mahasiswa }\end{array}$ \\
\hline
\end{tabular}




\begin{tabular}{|c|c|c|}
\hline $\begin{array}{l}\text { Sistem absensi } \\
\text { dosen } \\
\text { menggunakan } \\
\text { near field } \\
\text { communication } \\
\text { (nfc) technology } \\
\text { (Eko r Budi } \\
\text { Setiawan \& Bobi } \\
\text { Kurniawan, 2015) } \\
\text { [7] }\end{array}$ & 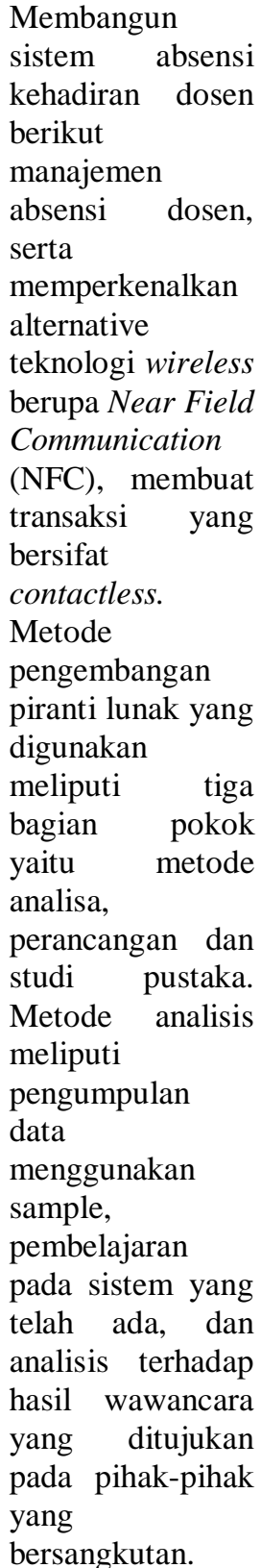 & $\begin{array}{l}\text { Rancangan } \\
\text { sistem } \\
\text { kehadiran } \\
\text { dosen yang } \\
\text { digunakan } \\
\text { pada saat } \\
\text { dosen } \\
\text { mengajar } \\
\text { (cek-in) dan } \\
\text { sesudah } \\
\text { mengajar } \\
\text { (cek-out). } \\
\text { Aplikasi } \\
\text { manajemen } \\
\text { absensi } \\
\text { dosen yang } \\
\text { digunakan } \\
\text { untuk me- } \\
\text { manajemen } \\
\text { data absensi } \\
\text { dosen dan } \\
\text { pencetakan } \\
\text { laporan } \\
\text { secara } \\
\text { harian, } \\
\text { mingguan, } \\
\text { bulanan } \\
\text { serta } \\
\text { tahunan }\end{array}$ \\
\hline
\end{tabular}

\section{G. Metodologi}

Konsep yang diterapkan dalam tahap perancangan Sistem Presensi dan Kedisiplinan Dosen adalah menggunakan model waterfall [5]. tahap-tahap dalam model waterfall, antara lain:

\section{a. Analisis Kebutuhan}

Proses pengumpulan kebutuhan perangkat lunak agar dapat dipahami perangkat lunak yang dibutuhkan oleh user seperti kebutuhan fungsional dan non fungsional. Spesifikasi kebutuhan perangkat lunak perlu didokumentasikan.

\section{b. Desain}

Proses berfokus pada desain pembuatan perangkat lunak termasuk struktur data, arsitektur perangkat lunak, representasi antar muka menggunakan tools $U M L$

\section{c. Pengkodean}

Harus ditranslasikan kedalam program perangkat lunak. Hasil dari tahap ini adalah program komputer sesuai dengan desain yang telah dibuat pada tahap desain. Untuk pengetikan script program pada aplikasi ini menggunakan pascal

\section{d. Pengujian}

Pengujian fokus pada perangkat lunak dari segi logik dan fungsional dan memastikan bahwa semua bagian sudah diuji

\section{Analisis dan Perancangan}

A. Analisis Kebutuhan Fungsional

a. Sistem dapat mengolah data dosen

b. Sistem dapat mengolah data kelas dan matakuliah

c. Sistem dapat mengolah jadwal dosen

d. Sistem dapat mengolah presensi dosen dan asisten

e. Sistem dapat mengolah kedisiplinan dosen

f. Sistem dapat mencetak rekapitulasi presensi dosen

g. Sistem dapat mencetak rekapitulasi kedisiplinan dosen

B. Analisis Kebutuhan Non Fungsional
a. Operasional
HD $250 \mathrm{~Gb}$
RAM $2 \mathrm{~Gb}$

Mouse dan Keyboard USB

Printer Canon IP2700

Sistem Operasi Windows 10

Borland Delphi 7.0

Database My SQL Enteprise

ODBC

Appserv

\section{b. Keamanan}

Menggunakan password login aplikasi dan basisdata

\section{c. Informasi}

Informasi jumlah mengajar dosen dan asisten Informasi jumlah ketidakdisiplinan dosen

\section{Perancangan Sistem}

Perancangan menggunakan tools UML diantaranya usecase diagram. Terdapat aktor staf tata usaha dan beberapa usecase. Rancangan usecase dapat dilihat pada gambar 3.1 . 


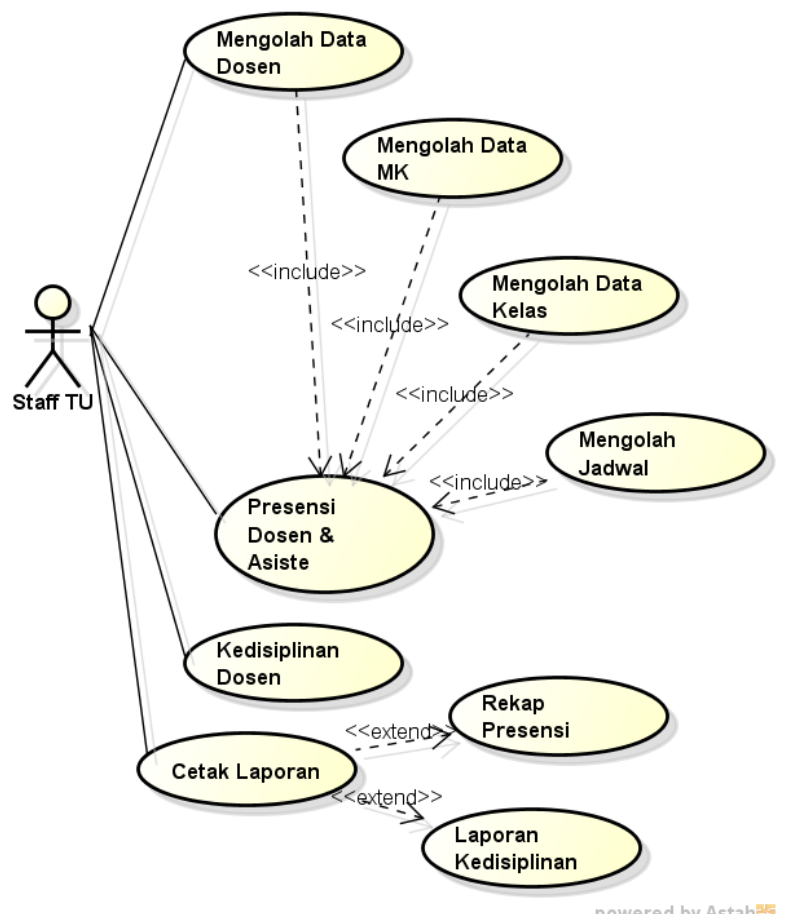

Gambar 1. Usecase Presensi Dosen dan Kedisiplinan

\section{Arsitektur Sistem}

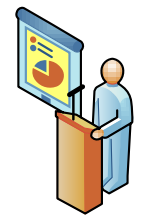

Dosen Mengajar

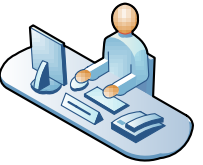

Bagian Keuangan
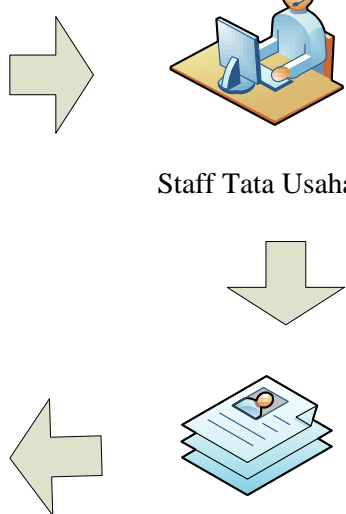

Rekapitulasi dan Lap Kedisiplinan Dosen
Gambar 2. Arsitektur Sistem Presensi dan Kedisiplinan Dosen

\section{Implementasi Dan Pembahasan}

Menggunakan sistem merupakan tahap meletakkan sistem agar siap dioperasikan.Tahap penggunaan sistem ini dilakukan setelah sistem selesai dievaluasi, kemudian peneliti melaksanakan pelatihan terhadap personil dengan memberi pengertian dan pengetahuan yang cukup tentang sistem informasi, posisi dan tugas setiap fungsi. Pelatihan ini untuk personil yang mengoperasikan sistem, yaitu staff tata usaha dosen. Hal ini dimaksudkan agar user memahami prosedur kerja sistem, dapat mengurangi kesalahan-kesalahan yang timbul yang dapat menghambat kelancaran operasional perusahaan

\section{A. Login}

Merupakan tampilan pertama pada saat program dijalankan.Tampilan form ini, berfungsi untuk keamanan data di mana pengguna diminta untuk meng-inputkan password yang telah ditentukan sebelumnya.

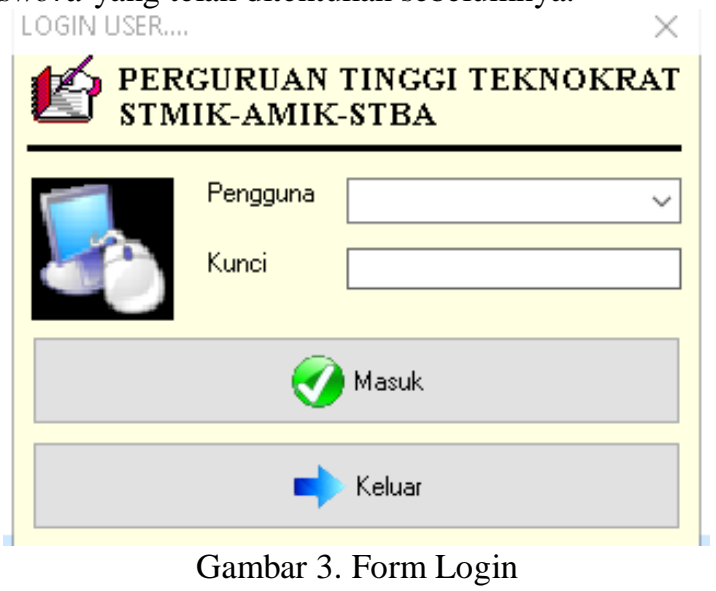

\section{B. Form Menu Utama}

Form ini merupakan menu utama dalam aplikasi karena berfungsi untuk mengakses menu-menu lainnya yang terdapat pada aplikasi. Tampilan menu utama program dapat di lihat pada gambar berikut

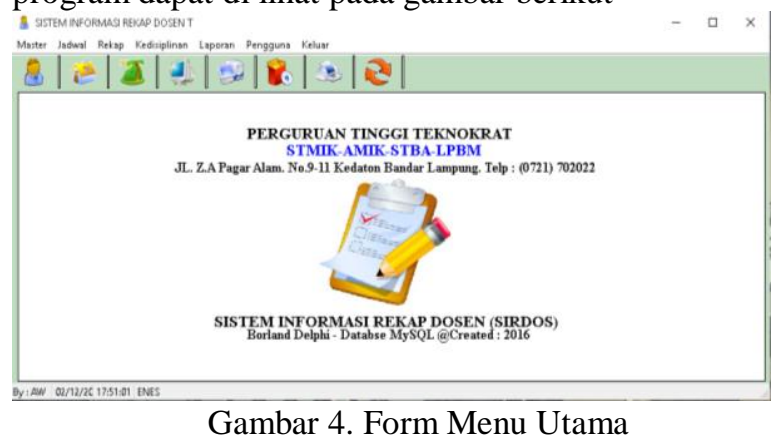

\section{Form Rekap Presensi}

Form ini digunakan oleh staff tata usaha untuk menginput data presensi dosen mengjar, menggantikan, mengwas uas dan pencarian data. Menggunakan presensi terkomputerisasi mengurangi penggunaan kertas dan manipulasi data presensi dosen mengajar

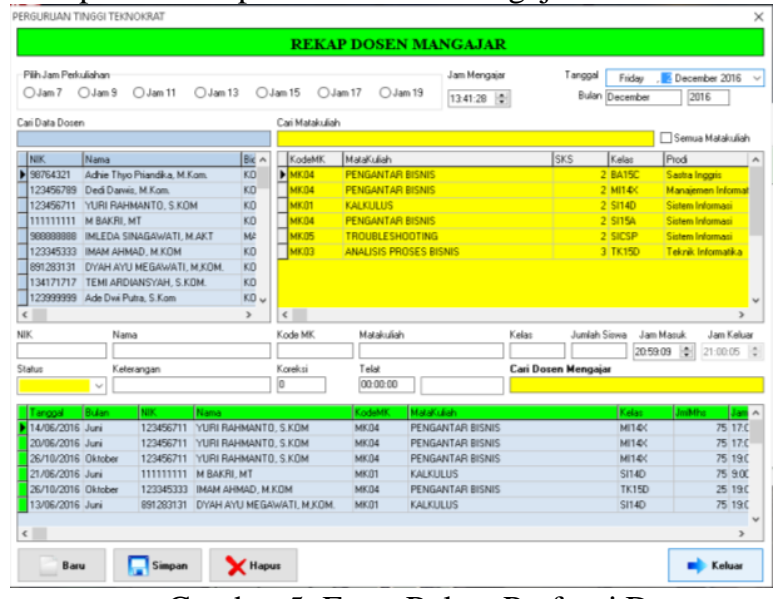

Gambar 5. Form Rekap Prefensi Dosen 


\section{Form Kedisiplinan Dosen}

Form ini digunakan untuk menginputkan data kedisiplinan atau ketidakhadiran dosen mengajar. Adanya aplikasi terkomputerisasi memudahkan staff tata usaha merekap kedisiplinan dosen

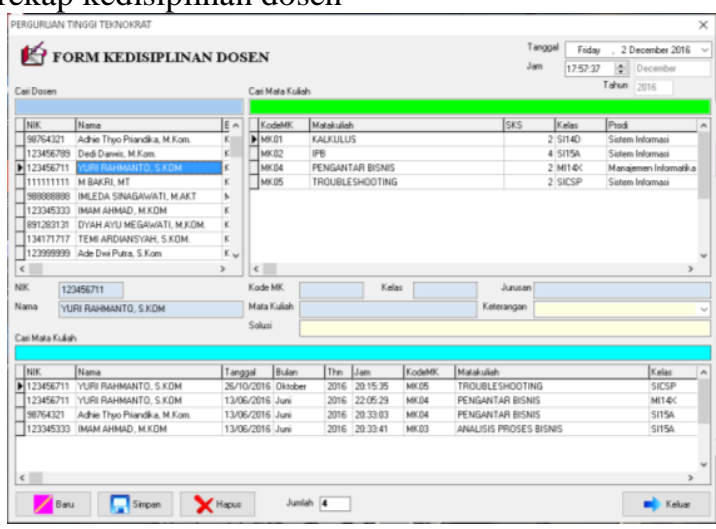

Gambar 6. Form Kedisiplinan Dosen

\section{E. Laporan Rekapitulasi Presensi Dosen}

Laporan ini berisi informasi dosen mengjar di instansi STMIK/AMIK/TBA, jumlah mengawas, koreksi, mengajar kelas besar dan kelas kecil

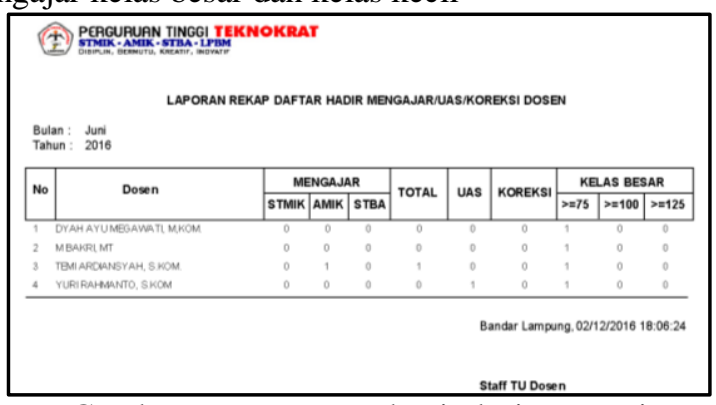

Gambar 7. Laporan Rekapitulasi Presensi

\section{F. Laporan Kedisiplinan Dosen}

Laporan ini berisi data kedisiplinan dosen yang tidak dapat mengjar beserta solusi yang telah diberikan.

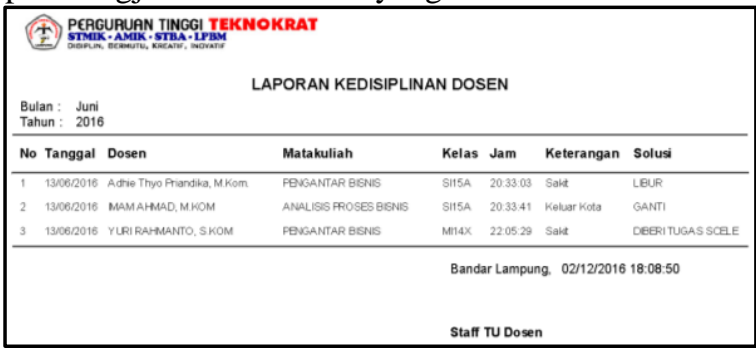

Gambar 8. Laporan Kedisiplinan Dosen

\section{G. Hasil Pembahasan}

Setelah menggunakan sistem komputerisasi, maka proses presensi dosen mengajar lebih menghemat biaya operasional pembelian kertas atau dapat menghemat Rp.576.000,- /tahun atau Rp.48.000,-/bulan. Mengurangi manipulasi presensi dan memercepat rekapitulasi presensi dosen selama 7 Jam. Rekapitulasi kedisiplinan dosen awalnya membutuhkan waktu 1 menit, menjadi 30 detik

\section{Kesimpulan Dan Saran}

\section{A. Simpulan}

Berdasarkan pembahasan yang telah dilakukan, dapat disimpulkan :

a. Adanya sistem terkomputerisasi dapat mengurangi manipulasi data karna semua presensi diolah oleh staff tata usaha secara langsung sehingga mengurangi manipulasi dan kesalahan presensi yang dilakukan dosen sehingga dapat mengurangi biaya operasional pembayaran gaji

b. Sistem terkomputerisasi mengurangi penggunaan kertas sebanyak 90\%. Semua presensi telah diinputkan kedalam basisdata. Penggunaan kertas 240 lembar setiap bulan sudah dapat dikurangi sehingga dapat mengurangi biaya operasional penggunaan kertas

c. Cara mempermudah rekapitulasi presensi dan kedisiplinan yaitu dengan sistem terkomputerisasi yang telah diinput kedalam basisdata, sehingga data mudah untuk dicetak langsung dari sistem. Proses rekapitulasi presensi awalnya membutuhkan waktu 8 jam, dengan sistem terkomputerisasi hanya 1 menit. Rekapitulasi kedisiplinan membutuhkan waktu 30 menit setiap minggu, saat ini cukup 30 detik sehingga dapat mempercepat rekapitulasi

d. Sistem presensi terkomputerisasi dapat digunakan oleh beberapa perguruan tinggi

\section{B. Saran}

Berdasarkan simpulan yang telah diuraikan, maka saran yang diberikan untuk sistem ini adalah:

a. Sistem presensi terintegrasi dengan bagian BAAKU dalam penginputan data matakuliah dan dosen pengampu

b. Melakukan bakcup data rutin agar menjaga data dari hal yang tidak diinginkan

\section{Daftar Pustaka}

[1] Al Fatta, Hanif. (2007). Analisis dan Perancangan Sistem Informasi, ANDI, 7

[2] Kamus Besar Bahasa Indonesia, 2016. Online

[3] Nuddin, M., Fithri. DL. (2005). "Sistem absensi asisten dosen menggunakan $Q R$ Code scannerccBerbasis android", ISSN,Vol.10, (Desember, 2005) : 2-8

[4] Nasution, D.E.P., (2009). Perancangan sistem informasi absensi dosen dan mahasiswa Universitas Sumatera Utara ISSN, Vol.11 (November, 2009) : $2-7$

[5] Rosa A.S dan Shalahuddin M. (2011).Rekayasa Perangkat Lunak - Terstruktur dan Berorientasi Objek. Modula, Bandung.

[6] Sutrisno, Edy. (2000). Management Sumber Daya Manusia; Jakarta, Prenada Kencana Group

[7] Setiawan, E.B., Kurniawan, Bobi. (2015). Sistem absensi dosen menggunakan near field communication (NFC) technology, ISSN (Oktober, 2015): 2-7

[8] Undang-Undang No.14 Th.(2005) 